\title{
Phadiatop testing in assessing predisposition to respiratory tract symptoms of allergic origin in athletes
}

\author{
Anton H de Waard, Edith M Peters
}

Objectives. To validate the use of the Phadiatop test as a predictor of allergy-associated respiratory tract symptoms (RTS) in trail runners.

Methods. The incidence of self-reported RTS was documented in 16 runners for 31 days and related to the Phadiatop status and circulating markers of allergic responses (changes in concentrations of serum $\operatorname{IgE}(\operatorname{sgE})$, differential leucocyte counts) at 8 time points before, during and after a 3 -day $95 \mathrm{~km}$ trail run.

Results. Twelve (75\%) athletes, of whom 7 (58\%) were Phadiatoppositive, presented with post-race RTS. A peak sIgE concentration
$>100 \mathrm{IU} / \mathrm{ml}$ accompanied RTS in only 4 (57\%) of the symptomatic Phadiatop-positive subjects. There was no significant difference between the eosinophil and basophil concentrations of the positive and negative groups $(p>0.05)$. One Phadiatop-negative subject presented with RTS as well as a peak sIgE concentration $>100$ $\mathrm{IU} / \mathrm{ml}$.

Conclusion. The Phadiatop assay does not accurately predict the development of post-exercise RTS of allergic origin in trail runners.

S Afr Med J 2012;102(5):309-311.
Since the early 1980s there has been concern about the high incidence of upper respiratory tract infections (URTIs) among athletes during periods of intensive exercise training and exhaustive endurance events. ${ }^{1,2}$ This results in interrupted training schedules and impaired performance in competitive events. Exercise immunologists have sought methods to identify the cause of these symptoms, which have now been extended to include the lower respiratory tract. ${ }^{3}$

Of post-exercise respiratory tract symptoms (RTS), $30-40 \%$ of cases are the result of infection, a further $30 \%$ are due to inflammation, and the final $30 \%$ are from unknown causes. ${ }^{2,4-6}$ Numerous theories have been proposed to account for the occurrence of non-infective post-exercise RTS, including the development of hyper-reactive airways, ${ }^{7}$ runaway inflammatory responses, ${ }^{8}$ reactivation of latent viral infection ${ }^{6}$ and allergic reactions. ${ }^{3,9}$

It has been documented that athletes experience higher rates of allergic disease than the general population ${ }^{10}$ and that the cited incidence of allergy among Olympic athletes is increasing. ${ }^{11}$ Exercise-induced symptoms of infection of the respiratory tract can mimic an allergic reaction, ${ }^{3}$ and exercise induces a $\mathrm{T}_{\mathrm{H}} 2$-dominant immunological shift; ${ }^{2}$ therefore, it may up-regulate an allergic response in those already sensitised. ${ }^{9}$ Increased exposure of athletes to irritants and allergens may contribute to this. ${ }^{3,11}$

Although the skin prick test (SPT) is generally accepted as the standard method for detecting IgE-related allergic sensitisation, ${ }^{12}$ its limitations include a lowered response in the elderly, greater difficulty in grading the response in dark-skinned persons, its contraindication in pregnancy, the quality and selection of allergens, and the theoretical risk of anaphylaxis. ${ }^{13}$

Specific IgE antibody testing is accepted as an alternative to the SPT. ${ }^{12}$ Combination tests such as the Phadiatop assay (Pharmacia \& Upjohn Diagnostics, Uppsala, Sweden) simultaneously test for IgE to a mixture of allergens causing common inhalant allergies.

Division of Human Physiology, School of Laboratory Medicine and Medical Sciences, College of Health Sciences, University of KwaZulu-Natal, Durban Anton $\mathrm{H}$ de Waard, $\mathrm{M}$ Tech Hom Edith M Peters, MSc (Med), PhD
Allergens included in the Phadiatop assay are Artemisia, dust mites (Dermatophagoides pteronyssinus and D. farinae), mixed moulds (Penicillium, Cladosporium, Aspergillus and Alternaria), pet dander (cat and dog), mixed grasses (Parietaria, Lolium, Phleum and Cynodon), and mixed trees (Acer, Betula, Olea, Salix, Pinus, Ulmus, Quercus, Eucalyptus, Acacia and Melaleuca). ${ }^{14}$ This assay has been found satisfactory for the diagnosis of IgE allergic sensitisation in the general population, with a sensitivity of $70.8 \%$ and a specificity of 90.7\% compared with the SPT. ${ }^{12}$

Our objectives were to: $(i)$ investigate the validity of the Phadiatop test as a predictor of allergy-associated RTS in athletes competing in a 3-day $95 \mathrm{~km}$ trail run, (ii) document the incidence of RTS before, during and after the event, and (iii) relate these incidences to the concentrations of serum IgE, leucocyte sub-classes and Phadiatop status of the athletes throughout and after the event.

\section{Methods}

This longitudinal study was part of a larger study examining physiological responses during the Three Cranes Challenge (a 3-day $95 \mathrm{~km}$ trail run) in Karkloof, KwaZulu-Natal on 25 - 27 February 2011. Local institutional ethical approval was obtained, and a sample of 22 volunteers signed informed consent forms.

After routine baseline testing on the afternoon before the race, venous blood samples were collected at a total of 8 time points, before and after each day's stage ( $\mathrm{S} 1_{\text {pre }}, \mathrm{S} 1_{\text {post }}, \mathrm{S} 2_{\text {pre' }}, \mathrm{S} 2_{\text {post }}, \mathrm{S} 3_{\text {pre }}$ and $\left.\mathrm{S} 3_{\text {post }}\right), 24$ hours post-race (24PR) and 72 hours post-race (72PR). RTS data were collected over a 31-day period, from 14 days prior to the race until the 14th day after the race. Of the 22 subjects, 16 completed the race and complied with all the study requirements. Two subjects were excluded as a result of failure to complete the race, and a further 4 did not complete post-race testing.

Athletes were asked to record the daily incidence and severity of RTS before, during and after the race using a graded 1 - 3-point scoring system. Symptoms monitored included cough, runny nose, sneezing, blocked nose, sore throat, headache, fever, tight chest and itchy eyes. A total RTS index score was determined using the sum of severity scores and the length of time that the symptom(s) persisted.

To determine which subjects qualified for post-exercise RTS, any subject presenting with a single RTS lasting $<2$ days or any nonspecific symptom (e.g. headache, itchy eyes) not accompanied by RTS lasting $>1$ day, was excluded. A peak post-stage or post-race serum $\operatorname{IgE}$ (sIgE) concentration below the clinically significant range 
(100 IU/ml) excluded the possibility of the RTS being of allergic origin.

Full blood counts, pre-race Phadiatop status and sIgE concentrations were determined by Ampath Laboratories, Howick, KwaZulu-Natal, using an automated UniCAP system. In the Phadiatop assay, concentrations $>0.35 \mathrm{IU} / \mathrm{ml}$ represented a positive response, irrespective of range. ${ }^{14}$

Exercise-induced changes in plasma volume (PV) over this 3-day event were determined from pre- and post-exercise haematocrit and haemoglobin concentrations. ${ }^{15}$ Post-exercise sIgE levels and concentration-dependent leucocyte counts were adjusted for percentage exercise-induced change in PV.

After confirmation of the absence of normality of the data, they were logarithmically transformed. A generalised linear model was applied to the median (range) sIgE and differential leucocyte concentration data from multiple subjects over multiple time points and between Phadiatop-positive and negative groups. The MannWhitney U-test was used to compare the RTS data pre- and postrace and between Phadiatop-positive and negative groups. Data are presented as the median (interquartile range (IQR)) in box-andwhisker plots in Figs 1 and 2. Significance was set at $p=0.05$.

\section{Results}

Of the 16 subjects ( 12 women, 4 men; age 25 - 50 years), 9 were Phadiatop-positive and 7 were Phadiatop-negative. The median and range of body mass index $(23.8,18.7-27.7$ v. $20.9,19.7-25.3)$ and percentage body fat $(20.9 \%, 15.7-29.3 \%$ v. $23.7 \%, 17.2-30.6 \%)$ did not differ significantly between Phadiatop-positive and negative groups. Baseline testing of vital signs was within the normal range, and subjects did not present with evidence of medical conditions that could have placed their health at risk. Table 1 presents the results of the Phadiatop assay and peak sIgE concentrations.

The criteria for post-race RTS were met by 12 (75\%) subjects, of whom 7 (58\%) were Phadiatop-positive and 5 (42\%) were Phadiatopnegative. The median (IQR) pre- and post-race RTS index scores of the Phadiatop groups did not differ significantly $(p>0.05)$ (Fig. 1).

Fig. 2 presents the median (IQR) sIgE concentrations of the subjects (adjusted for PV). There was a non-significant $(p=0.37)$ rise in the sIgE concentrations of the entire group over the course of testing, with highest concentrations recorded in $75 \%$ of subjects at the 24PR time period. There was a highly significant $(p<0.001)$ difference between the sIgE concentrations of the Phadiatop-positive and negative groups.

Concentrations of sIgE reached clinical significance (peak sIgE $>100 \mathrm{IU} / \mathrm{ml}$ ) in 5 (42\%) of the 12 RTS-positive subjects (4 Phadiatoppositive and RTS-positive subjects and 1 Phadiatop-negative and RTS-positive subject).

There was no significant exercise-induced elevation in PV-adjusted concentrations of either basophils or eosinophils over time ( $p>0.05)$, and the difference between Phadiatop-positive and negative groups in terms of eosinophil or basophil response to 3 days of exercise was not significant $(p>0.05)$.

\section{Discussion}

The incidence of post-exercise RTS in endurance runners in this study $(n=12,75 \%)$ was higher than that in most other reported studies, ${ }^{1-3}$ possibly owing to the inclusion of subjects with a prior history of allergy; in most previous studies, allergy was seen as a confounding factor in determining the incidence of URTI and was therefore excluded.

Interestingly, in this field trial, subjects with systemic evidence of RTS associated with an allergic reaction accounted for $42 \%(n=5)$ of the 12 cases with post-exercise RTS. However, as seen by the lack of significance between post-race RTS incidence in Phadiatoppositive and negative groups (Fig. 1), the incidence of post-race RTS symptoms was not defined by the Phadiatop test.

Our primary finding was that, of the 7 Phadiatop-positive subjects who developed post-race RTS, only 4 (58\%) displayed clinically elevated sIgE concentrations above the cut-off point for allergy (sIgE $>100 \mathrm{IU} / \mathrm{ml}$ ). The mildly elevated eosinophil concentrations often seen in allergic responses ${ }^{13}$ were not evident in the Phadiatop-positive group ( $p>0.05)$.

Although specific sIgE antibody testing (SPT) provides evidence of sensitisation to an allergen, an allergic disease response only develops once the individual is exposed to that particular allergen; therefore, although the Phadiatop test may provide satisfactory accuracy in identifying predisposition to allergic responsiveness to airborne allergens, on its own it may not predict the development of allergic

Table 1. Phadiatop assay results and peak race-induced sIgE concentrations of the 16 subjects

\begin{tabular}{|c|c|c|c|c|c|}
\hline \multicolumn{3}{|c|}{$\begin{array}{l}\text { Phadiatop-positive } \\
\qquad(n=9)\end{array}$} & \multicolumn{3}{|c|}{$\begin{array}{l}\text { Phadiatop-negative } \\
(n=7)\end{array}$} \\
\hline Subject & $\begin{array}{l}\text { Phadiatop result } \\
\text { (sIgE conc.) (IU/ml) }\end{array}$ & $\begin{array}{l}\text { Peak sIgE conc. } \\
(\mathrm{IU} / \mathrm{ml})^{\dagger} \text { (time-point) }\end{array}$ & Subject & $\begin{array}{l}\text { Phadiatop result } \\
\text { (sIgE conc.) }(\mathrm{IU} / \mathrm{ml})\end{array}$ & $\begin{array}{l}\text { Peak sIgE conc. } \\
(\mathrm{IU} / \mathrm{ml})^{\dagger} \text { (time-point) }\end{array}$ \\
\hline 1 & 8.51 & 85.64 (24PR) & 5 & 0.13 & 23.64 (24PR) \\
\hline 2 & 75.80 & 227.14 (24PR) & 6 & 0.17 & 19.46 (72PR) \\
\hline 3 & 7.55 & 54.38 (24PR) & 10 & 0.12 & 55.44 (24PR) \\
\hline 4 & 0.41 & 56.32 (24PR) & 12 & 0.28 & 33.58 (24PR) \\
\hline 7 & 7.19 & 445.74 (24PR) & 14 & 0.12 & $11.30(24 \mathrm{PR})$ \\
\hline 8 & 3.42 & 240.48 (72PR) & 15 & 0.14 & 140.82 (24PR) \\
\hline 9 & 0.50 & $76.13(24 \mathrm{PR})$ & 16 & 0.11 & 66.79 (24PR) \\
\hline 11 & 9.49 & 63.14 (24PR) & & & \\
\hline 13 & 41.30 & $274.0\left(\mathrm{~S} 1_{\mathrm{pre}}\right)$ & & & \\
\hline Median & $7.55^{\ddagger}$ & $85.64^{\ddagger}$ & Median & 0.13 & 33.58 \\
\hline
\end{tabular}




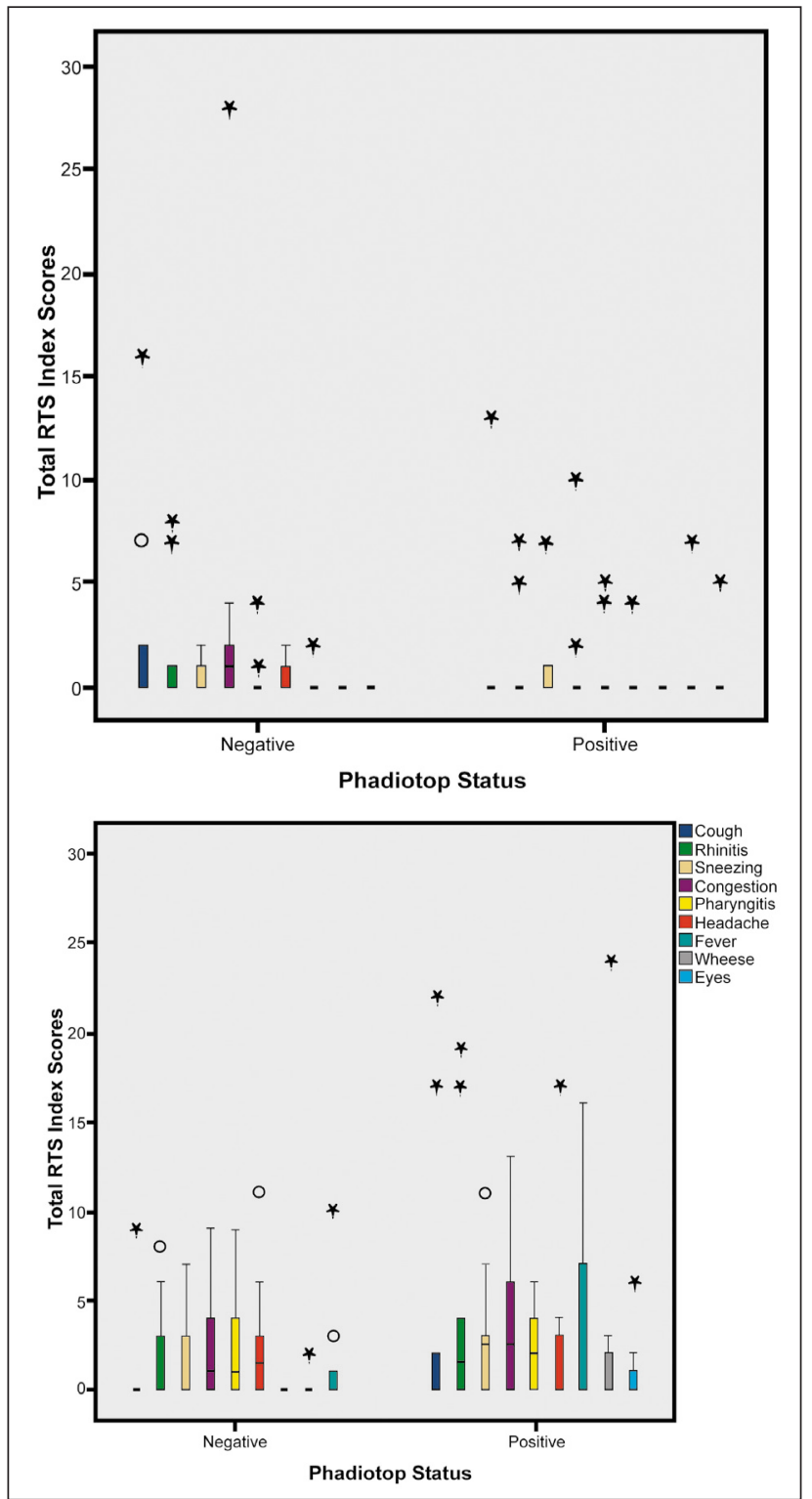

Fig. 1. Median (IQR) pre- (left) and post-race (right) total RTS index scores of Phadiatop-positive ${ }^{*}(n=9)$ and negative $(n=7)$ groups. $\left({ }^{*}\right.$ sIgE concentration $>0.35 \mathrm{IU} / \mathrm{ml}$ in Phadiatop assay)

disease in trail runners. Owing to the fixed selection of allergens, it is theoretically possible to miss subjects who are sensitised to less common inhalant allergens (such as local flora or fauna), as was the case in one of our subjects.

The predictive validity of the Phadiatop assay for the incidence of exercise-induced RTS of allergic origin in the trail runners must therefore be questioned.

Acknowledgements. Ms Heidi Mocke and the Wildlands Conservation Trust are thanked for permitting the collection of these data at the 2011 Three Cranes Challenge multi-day trail run and for providing the research team with accommodation in the 'race village' located in the Bushwillow Campsite. Dr Rentia Dennisen, Professor Andrew Mckune, Mr Navin Singh and Mr Ronnie Naicker

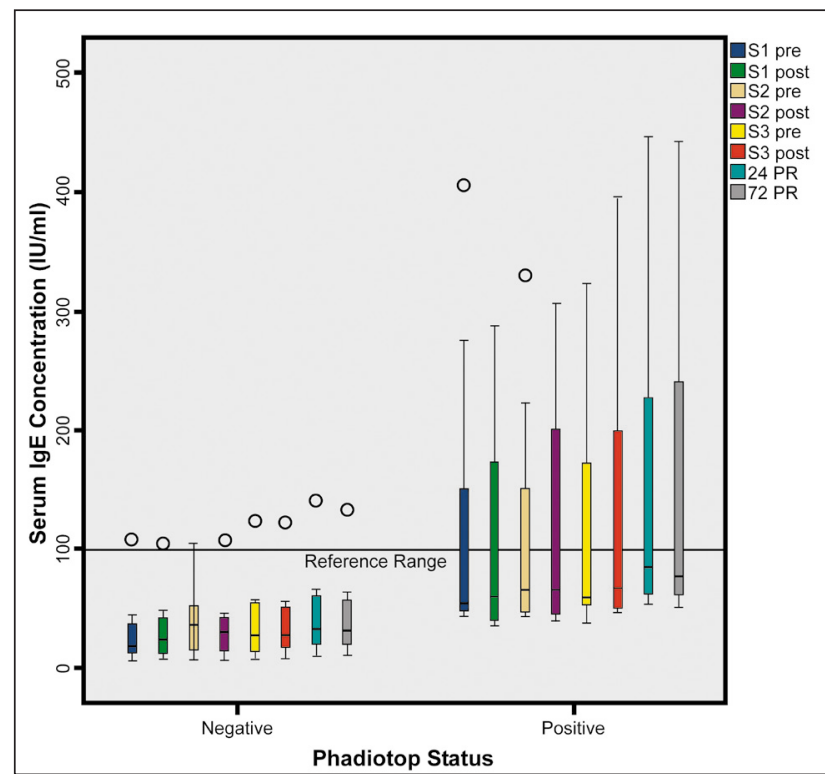

Fig. 2. Median (IQR) of absolute sIgE* concentrations ${ }^{\dagger}$ of Phadiatop-positive and negative groups, at 8 stages during and after a 3-day $95 \mathrm{~km}$ trail run. $\left({ }^{*}\right.$ Adjusted for plasma volume; ${ }^{\dagger}$ Reference range 0 - $100 \mathrm{IU} / \mathrm{ml}$ )

are thanked for their support with the field-side collection of data reported in this article. Mr Asokaran Rajh is thanked for his assistance with the graphic artwork.

\section{References}

1. Peters EM, Bateman ED. Ultramarathon running and upper respiratory tract infections. S Afr Med J 1983;64:582-584. [PMID: 6623247]

2. Walsh NP, Gleeson M, Shephard RJ, et al. Position statement. Part 1: Immune function and exercise. Exerc Immunol Rev 2011;17:6-63. [PMID: 21446352]

Schwellnus M, Lichaba M, Derman W. Respiratory tract symptoms in endurance athletes - a review of causes and consequences. Current Allergy \& Clinical Immunology 2010;3(2):3-9.

4. Spence L, Brown WJ, Pyne DB, et al. Incidence, etiology, and symptomatology of upper respiratory illness in elite athletes. Med Sci Sports Exerc 2007;39(4):577-586. [http://dx.doi.org/10.1249/ mss.0b013e31802e851a] [PMID: 17414793]

5. Cox AJ, Gleeson M, Pyne DB, Callister R, Hopkins WG, Fricker PA. Clinical and laboratory evaluation of upper respiratory symptoms in elite athletes. Clin J Sport Med 2008;18(5):438-445. [http://dx.doi. org/10.1097/JSM.0b013e318181e501] [PMID: 18806552]

6. Reid VL, Gleeson M, Williams N, Clancy RL. Clinical investigation of athletes with persistent fatigue and/or recurrent infections. Br J Sports Med 2004;38:42-45 [PMID: 14751944]

Anderson SD, Kippelen P. Airway injury as a mechanism for exercise-induced bronchoconstriction in elite athletes. J Allergy Clin Immunol 2008;122(2):225-235. [http://dx.doi.org/10.1016/j. jaci.2008.05.001] [PMID: 18554705]

8. Bermon S. Airway inflammation and upper respiratory tract infection in athletes: is there a link? Exerc Immunol Rev 2007;13:6-14. [PMID: 18198657]

Immunol Rev 2007,13:6-1 Peters E M. Postrace upper respiratory tract infections' in ultramarathon
inflammation? South African Journal of Sports Medicine 2004;16(1):52-57.

inflammation? South African Journal of Sports Medicine 2004;16(1):52-57.
10. Thomas S, Wolfarth B, Wittmer C, Nowak D, Radon K, GA2LEN-Olympic StudyTeam. Self-reported 10. Thomas S, Wolfarth B, Wittmer C, Nowak D, Radon K, GA2LEN-Olympic StudyTeam. Self-reported
asthma and allergies in top athletes compared to the general population: results of the German part of the GA2LEN-Olympic Study, 2008. Allergy, Asthma \& Clinical Immunology 2010;6:31. [http://dx.doi. org/10.1186/1710-1492-6-31] [PMID: 21118543]

11. Bonini S, Bonini M, Bousquet J, et al. Rhinitis and asthma in athletes: an ARIA document in collaboration with GA2LEN. Allergy 2006;61(6):681-692. [http://dx.doi.org/10.1111/j.13989995.2006.01080.x] [PMID: 16677236]

12. Vidal C, Gude F, Boquete O, et al. Evaluation of the Phadiatop test in the diagnosis of allergic sensitization in a general adult population. J Investig Allergol Clin Immunol 2005;15(2):124-130. [PMID: 16047713]

13. Morris A. Atopy, anamnesis and allergy testing. InnovAiT 2009;2(3):158-165. [http://dx.doi. org/10.1093/innovait/inp001]

14. Garcia-Marcos L, Sanchez-Solis M, Martinez-Torres AE, Lucas Moreno JM, Hernando Sastre V. Phadiatop compared to skin-prick test as a tool for diagnosing atopy in epidemiological studies in schoolchildren. Pediatr Allergy Immunol 2007:18:240-244. [http://dx.doi.org/10.1111/j.13993038.2006.00508.x] [PMID: 17346300]

15. Dill DB, Costill DL. Calculation of percentage changes in volumes of blood, plasma and red cells in dehydration. J Appl Physiol 1974; 37(2):247-248. [PMID: 4850854]

Accepted 9 February 2012. 